\title{
Características morfológicas e produtivas da maniçoba cultivada sob lâminas hídricas e doses de nitrogênio
}

\author{
Morphological and productive characteristics of cassava grown under irrigation and \\ nitrogen levels
}

\author{
ARAÚJO FILHO, José Teodorico de ${ }^{1}$; PAES, Reinaldo de Alencar ${ }^{1}$; AMORIM, Philipe \\ Lima $\mathrm{de}^{2^{*}}$; COMASSETTO, Fernanda Ferreira ${ }^{3}$; SILVA, Silvia Comasseto da ${ }^{4}$
}

\author{
${ }^{1}$ Universidade Federal de Alagoas, Centro de Ciências Agrárias, Rio Largo, Alagoas, Brasil. \\ ${ }^{2}$ Universidade Federal de Viçosa, Centro de Ciências Agrárias, Departamento de Zootecnia, Viçosa, \\ Minas Gerais, Brasil. \\ ${ }^{3}$ Universidade Federal do Pampa, departamento de Agronomia, Itaqui, Rio Grande do Sul, Brasil. \\ ${ }^{4}$ Universidade Federal de Santa Maria, Centro de Ciências Rurais, Departamento de Medicina \\ Veterinária, Santa Maria, Rio Grande do Sul, Brasil. \\ *Endereço para correspondência: philipe.amorim@ufv.com
}

\section{RESUMO}

Objetivou-se com este ensaio avaliar o comportamento da maniçoba cultivada sob irrigação e doses de nitrogênio. O delineamento experimental utilizado foi $\mathrm{o}$ de blocos completos casualizados em arranjo fatorial (7 x 4), sendo sete lâminas totais de água $(394,28$, $333,16, \quad 279,20, \quad 213,00, \quad 209,00, \quad 169,16$ e $116,60 \mathrm{~mm})$ e quatro doses de nitrogênio (ausência, 50, 100 e 150kg/ha), com duas repetições. As avaliações foram realizadas aos 60 e 120 dias após corte de uniformização. Aos 60 e 120 dias não houve interação entre os fatores lâminas hídricas e doses de nitrogênio para todas as características morfológicas. As doses de nitrogênio e lâminas hídricas separadamente exerceram efeito linear positivo sobre as variáveis altura de plantas, número de folhas, número de bifurcações, diâmetro de caule e área de copa aos 60 dias. Apenas para a característica número de folhas e eficiência de utilização do nitrogênio foram detectadas interações significativas entre os fatores aos 120 dias. As doses de nitrogênio imprimiram efeito linear positivo sobre as características morfológicas altura de plantas, número de bifurcações, diâmetro de caule, área de copa, produção de massa fresca e produção de massa seca e eficiência de utilização da água aos 120 dias. Observou-se efeito semelhante para o fator lâmina hídrica, no entanto não foi observada diferença significativa para as características área de copa. As características morfológicas e produtivas da maniçoba são incrementadas com a utilização da adubação nitrogenada e irrigação.

Palavras-chave: forrageira nativa, Manihot pseudoglazovii, produtividade, semiárido

\section{SUMMARY}

The objective of this research to evaluate the behavior of cassava cultivated under irrigation and nitrogen levels. The experimental design was a randomized complete block in factorial arrangement (7 x 4), seven water slides (394.28, $333.16,279.20,213.00,209.00,169.16$ and $116.60 \mathrm{~mm})$ and four levels of nitrogen (absence, 50, 100 and $150 \mathrm{~kg} / \mathrm{ha}$ ) with two replications. Evaluations were performed at 60 and 120 days of regrowth. At 60 and 120 days there was no interaction between water slides and nitrogen for all morphological characteristics. The nitrogen and water slides separately exerted positive linear effect on the variables plant height, number of leaves, number of bifurcations, stem diameter and canopy area at 60 days. Just for the characteristic number of leaves and nitrogen use efficiency were detected significant interactions between factors at 120 days. Nitrogen rates exerted positive linear effect on the morphological characteristics of plant height, 
number of bifurcations, stem diameter, canopy area, fresh matter yield, dry matter yield and water use efficiency at 120 days. Similar effect was observed for the factor water slides, however no significant difference was observed for the characteristic canopy area. The morphological characteristics and production of cassava are increased with the use of nitrogen fertilizer and irrigation.

Keywords: Manihot pseudoglazovii, native forage, semiarid, yield

\section{INTRODUÇÃO}

A maniçoba (Manihot pseudoglazovii), assim como outras plantas nativas da Caatinga, pode ser considerada um importante recurso forrageiro de uso estratégico, apresentando-se como alternativa alimentar, para os períodos de menor disponibilidade de forragens (ARAÚJO FILHO et al., 2011). No entanto, considerando-se o ciclo fenológico da espécie, a mesma apresenta severa estacionalidade produtiva nos períodos secos, dada a ausência principalmente de água $\mathrm{e}$ nutrientes.

O semiárido nordestino é caracterizado por duas estações: chuvosa e seca. A estação chuvosa é caracterizada principalmente pela alta precipitação, com relativa harmonia entre os fatores de crescimento (água, nutrientes, luz e temperatura), favorecendo desse modo a produção forrageira, com a concomitante elevação dos índices zootécnicos dos rebanhos, comuns dessa estação. Apesar dos principais fatores de crescimento das plantas estarem abundantes no período seco do ano, a baixa disponibilidade de água não permite que os demais sejam utilizados de maneira eficiente nos processos fotossintéticos, intensificando assim os processos de senescência e abscisão das folhas.
O conhecimento das principais causas da estacionalidade produtiva das plantas forrageiras permite o planejamento de estratégias de manejo de modo a proporcionar maior distribuição da oferta de forragem durante o ano.

A irrigação tem sido utilizada como estratégia de manejo para diminuir a sazonalidade produtiva comum do período seco. No entanto, sua utilização deve ser avaliada de maneira criteriosa, pois, a disponibilidade de água será o fator preponderante da adoção ou rejeição dessa tecnologia, uma vez que esse "bem" não está disponível em abundância no semiárido nordestino.

De modo a otimizar a utilização da irrigação, se faz necessário a utilização concomitante de fertilizantes (principalmente os nitrogenados), uma vez que devido a características intrínsecas aos processos pedogênicos dos solos do semiárido nordestino, os mesmos apresentam baixos teores de matéria orgânica e, consequentemente, baixa disponibilidade de nitrogênio, principalmente (CUNHA et al., 2012).

Objetivou-se com este trabalho avaliar o comportamento da maniçoba cultivada sob lâminas hídricas e doses de fertilizante nitrogenado.

\section{MATERIAL E MÉTODOS}

O trabalho foi conduzido no período de janeiro a novembro de 2004 no município de Macaíba, Rio Grande do Norte, Brasil. A análise química das amostras do solo utilizado revelou: $\mathrm{pH}$ $\left(\mathrm{H}_{2} \mathrm{O}\right)=5,3 ; \mathrm{P}$ disponível $($ Mehlich $)=$ $0,54 \mathrm{mg} / \mathrm{dm}^{3} ; \mathrm{K}$ disponível $($ Mehlich $)=$ $63 \mathrm{mg} / \mathrm{dm}^{3} ; \mathrm{Na}^{+}=0,03 \mathrm{cmol}_{\mathrm{c}} / \mathrm{dm}^{3}, \mathrm{H}^{+}+$ $\mathrm{Al}^{+3}=6,6, \mathrm{Al}^{+3}=0,70 \mathrm{cmol}_{\mathrm{c}} / \mathrm{dm}^{3} ; \mathrm{Ca}^{+2}$ $=0,70 \mathrm{cmol}_{\mathrm{d}} / \mathrm{dm}^{3} ; \mathrm{Mg}^{+2}=0,75 ; \mathrm{SB}=$ $1,64 \mathrm{cmol}_{\mathrm{C}} / \mathrm{dm}^{3} ; \mathrm{CTC}=8,24 \mathrm{cmol}_{\mathrm{C}} / \mathrm{dm}^{3} \mathrm{e}$ matéria orgânica $=25,94 \mathrm{~g} / \mathrm{dm}^{3}$. 
O delineamento experimental utilizado foi o de blocos completos casualizados (devido à heterogeneidade do solo entre os blocos), distribuídos em arranjo fatorial ( $7 \times 4)$, sendo sete lâminas totais de água $(394,28,333,16,279,20$, $213,00,209,00,169,16$ e $116,60 \mathrm{~mm})$ e quatro doses de nitrogênio (ausência, $50,100$ e $150 \mathrm{~kg} / \mathrm{ha})$, com duas repetições.

As sementes de maniçoba (Maniçoba pseudoglazovii) foram postas a germinar em sementeira convencional, e aos 45 dias após a semeadura, as plântulas foram transplantadas para sacos de polietileno preto $(23 \times 13 \mathrm{~cm})$, onde permaneceram por 105 dias, sendo, em seguida, transplantadas para o campo experimental.

O solo foi preparado mediante aração e gradagem e posteriormente aplicados 1,4t/ha de calcário dolomítico. Em seguida foi realizada a abertura das covas, e a adubação de fundação foi realizada por meio da aplicação de um quilo de adubo orgânico curtido em todas as covas. As mudas de maniçoba foram alocadas nas parcelas experimentais utilizando-se uma densidade de plantio de 6.666 plantas/ha $(1,5 \times 1,5 \mathrm{~m})$. No dia primeiro de agosto de 2004 foi efetuado um corte a $20 \mathrm{~cm}$ do solo em todas as plantas, com o objetivo de uniformizá-las, em seguida iniciou os tratamentos com a irrigação e a adubação nitrogenada.

A distribuição da água pela irrigação se deu por intermédio do sistema de aspersão, onde a pressão de serviço utilizada foi de $0,8 \mathrm{MPa}$, sendo esta, dentre as pressões testadas, a que se obteve uma curva de redução da precipitação do centro para lateral mais regular (Figura 1).

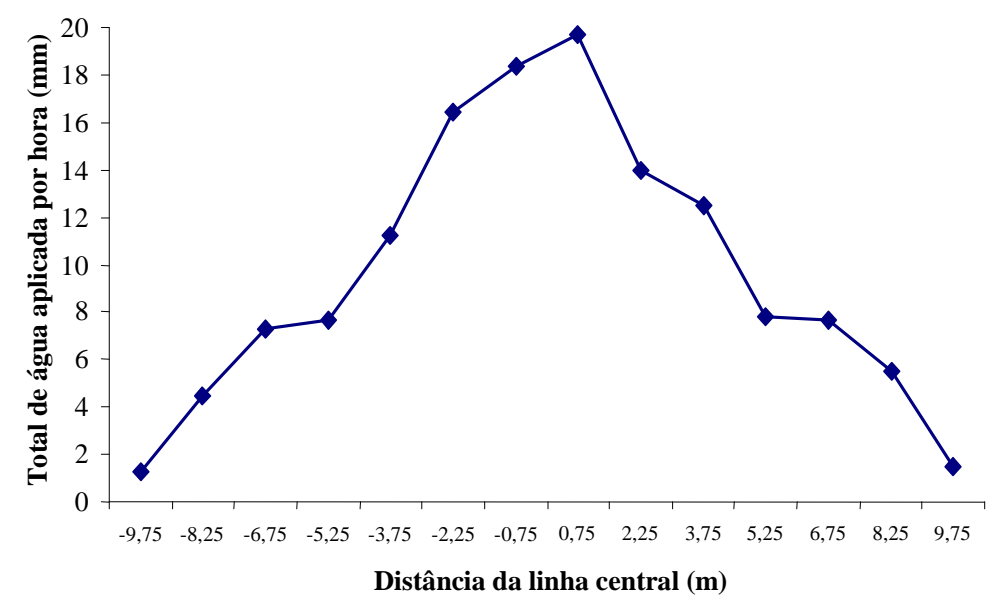

Figura 1. Variação do total de água aplicada em uma hora de irrigação em função da linha central de aspersores (origem) para o lado direito (distâncias negativas) e esquerdo (distâncias positivas), utilizando-se uma pressão de serviço de $0,8 \mathrm{Mpa}$

Foram realizadas dezesseis irrigações semanais com uma hora de duração cada. Os dados referentes à precipitação pluviométrica natural durante o ano de
2004 e quantidade total de água (chuva + irrigação) medidas nas linhas de plantio durante o período experimental 
podem ser observadas nas Figuras 2 e 3 respectivamente.

As parcelas foram constituídas de 14 linhas de plantio, posicionadas em paralelo com a linha central de aspersores, sendo sete de cada lado. Cada linha foi dividida em quatro parcelas, com seis plantas úteis em cada, onde foi realizada a adubação nitrogenada.

A adubação nitrogenada foi dividida em duas aplicações, sendo a primeira $(33 \%)$ aplicada logo após o corte, e a segunda (66\%) trinta dias após o corte de uniformização.

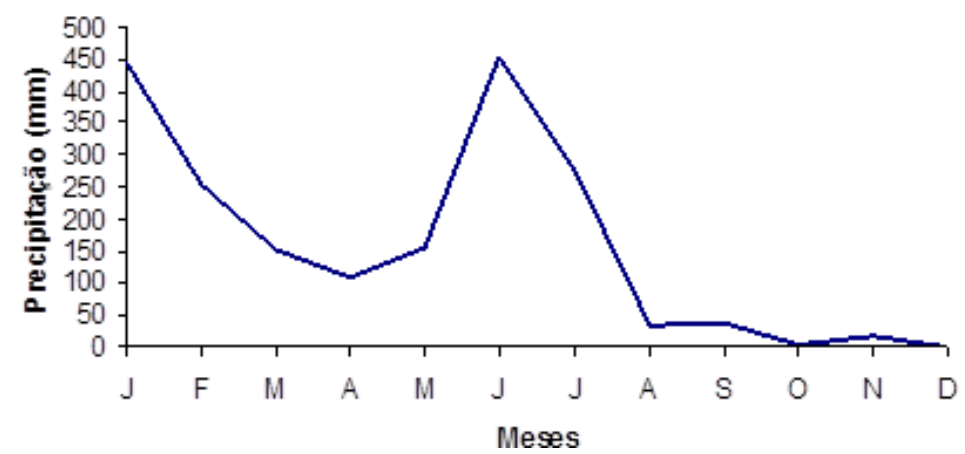

Figura 2. Precipitação natural ocorrida no ano de 2004, no município de Macaíba-RN. Fonte: EMPARN

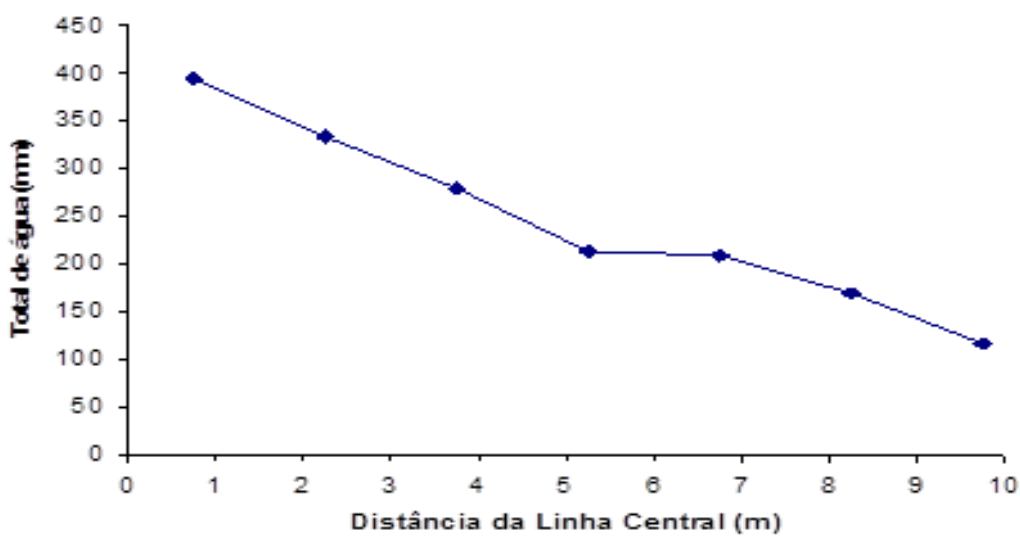

Figura 3. Quantidade total de água (chuva + irrigação) medidas nas linhas de plantio durante o ciclo fenológico da maniçoba

A fonte de nitrogênio utilizada foi a ureia. O fósforo e o potássio foram aplicados de acordo com a recomendação do laboratório de química e fertilidade do solo. As fontes utilizadas foram $o$ superfosfato simples e o cloreto de potássio.
Sessenta dias após o corte de uniformização mediu-se altura de planta (cm), número de folhas, área da copa $\left(\mathrm{cm}^{2}\right)$, diâmetro do caule $(\mathrm{cm})$ e o número de bifurcações em todas as plantas úteis do experimento, sendo medidas novamente aos 120 dias após corte de uniformização. A altura média das plantas 
foi determinada pela medição da planta a partir do nível do solo até a extremidade de sua folha mais alta, o número de folhas pela contagem de todas as folhas, a área da copa através da determinação da média do seu diâmetro, onde posteriormente foi determinada sua área, o diâmetro da base do caule foi medido a $10 \mathrm{~cm}$ do solo com o auxílio do paquímetro e o número de bifurcações através da contagem de todas as bifurcações da planta.

Todas as plantas foram cortadas aos 120 dias, a $20 \mathrm{~cm}$ do solo, quando a maior parte das plantas se encontrava no início da frutificação. As plantas colhidas foram transportadas para o laboratório da Escola Agrícola de Jundiaí (UFRN), onde foi determinada a produção de massa fresca através da pesagem da parte superior da planta colhida e a produção de massa seca, onde estas foram postas para secar em estufa de circulação forçada de ar à $55^{\circ} \mathrm{C}$, até peso constante.

A eficiência de utilização de nitrogênio ( $\mathrm{kg}$ de $\mathrm{MS} / \mathrm{kg}$ de $\mathrm{N}$ ) foi estimada dividindo-se a produção de massa seca (kg/ha) pela dose de nitrogênio aplicada. A eficiência de utilização da água (kg de MS/mm de água) foi obtida da razão entre a produção de massa seca e quantidade total de água aplicada (irrigação + precipitação).

A análise de variância foi realizada a $5 \%$ de probabilidade para o erro tipo I. O grau de ajustamento dos modelos foi avaliado pelo coeficiente de determinação e pela significância dos coeficientes de regressão, testada pelo teste $\mathrm{t}$ corrigido com base nos resíduos da análise de variância.

\section{RESULTADOS E DISCUSSÃO}

Não houve interações significativas $(\mathrm{P}>0,05)$ entre as lâminas hídricas e as doses de nitrogênio para as características morfológicas avaliadas aos 60 dias. Avaliando-se os efeitos dos fatores isolados sobre as características morfológicas da maniçoba, constatou-se que houve diferenças significativas $(\mathrm{P}<0,05)$ para as variáveis altura de plantas, número de folhas, número de bifurcações, diâmetro de caule e área de copa (Figuras 4 e 5).

As doses de nitrogênio exerceram efeito linear positivo $(\mathrm{P}<0,05)$ sobre as características altura de plantas, número de folhas, número de bifurcações, diâmetro de caule e área de copa (Figura 4).

A prioridade no destino do nitrogênio absorvido pela planta são órgãos $\mathrm{e}$ tecidos mais jovens, principalmente as folhas. Com aumento da disponibilidade de nitrogênio uma maior quantidade de folhas e ramos no topo do dossel pode ser produzida, elevando desse modo os valores da característica altura de planta (Figura 4). A elevação do número de folhas acarretou na elevação das demais características morfológicas, pois, as folhas são os componentes botânicos mais fotossinteticamente ativos na planta, sendo responsáveis pela síntese de compostos orgânicos essenciais ao crescimento e ao desenvolvimento da planta. A elevação nos valores da característica número de bifurcações auxiliou diretamente o aumento do número de folhas e também na área da copa, pois, com a elevação do seu número, há um aumento concomitante no número de gemas, proporcionando assim um maior número de pontos de emissão de folhas, aumentando consequentemente a área da copa da planta.

O aumento do diâmetro do caule com a elevação das doses de nitrogênio pode ser decorrente ao aumento no fluxo de nutrientes entre as raízes e a parte aérea, necessitando assim do espessamento de 
tecidos de condução, para que esses nutrientes cheguem de maneira eficiente e supram as demandas da parte aérea. Os valores dessa característica podem ter-se elevado também pelo fato da planta necessitar suportar o aumento no peso da parte aérea à medida que se elevou as doses de nitrogênio.
$\mathrm{O}$ fator isolado lâminas hídricas imprimiu efeito linear positivo $(\mathrm{P}<0,05)$ sobre as características morfológicas altura de plantas, número de folhas, área de copa, número de bifurcações e diâmetro de caule aos 60 dias (Figura 5).
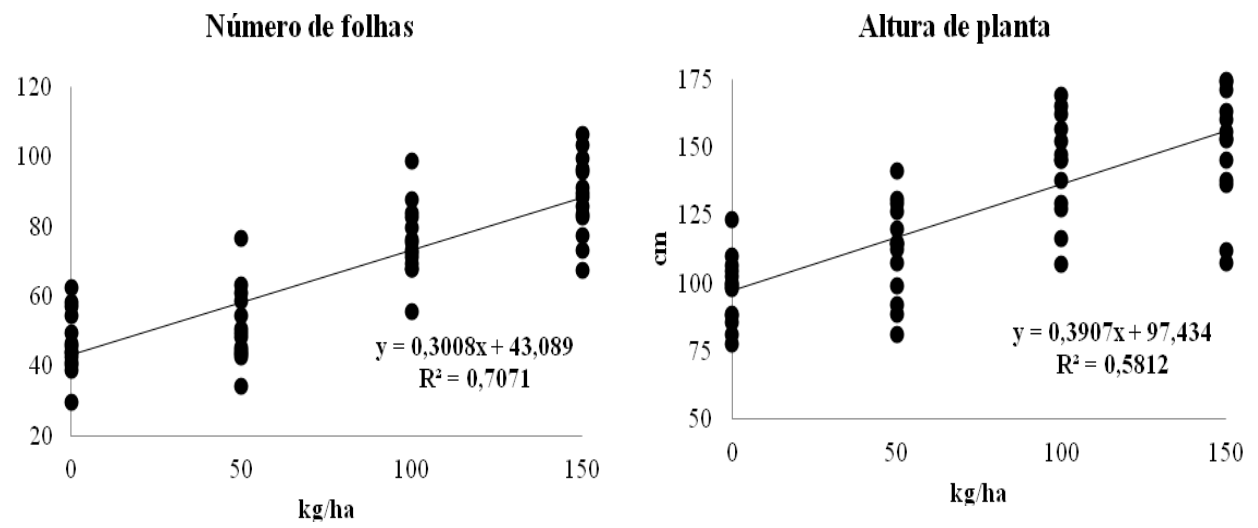

Área de copa
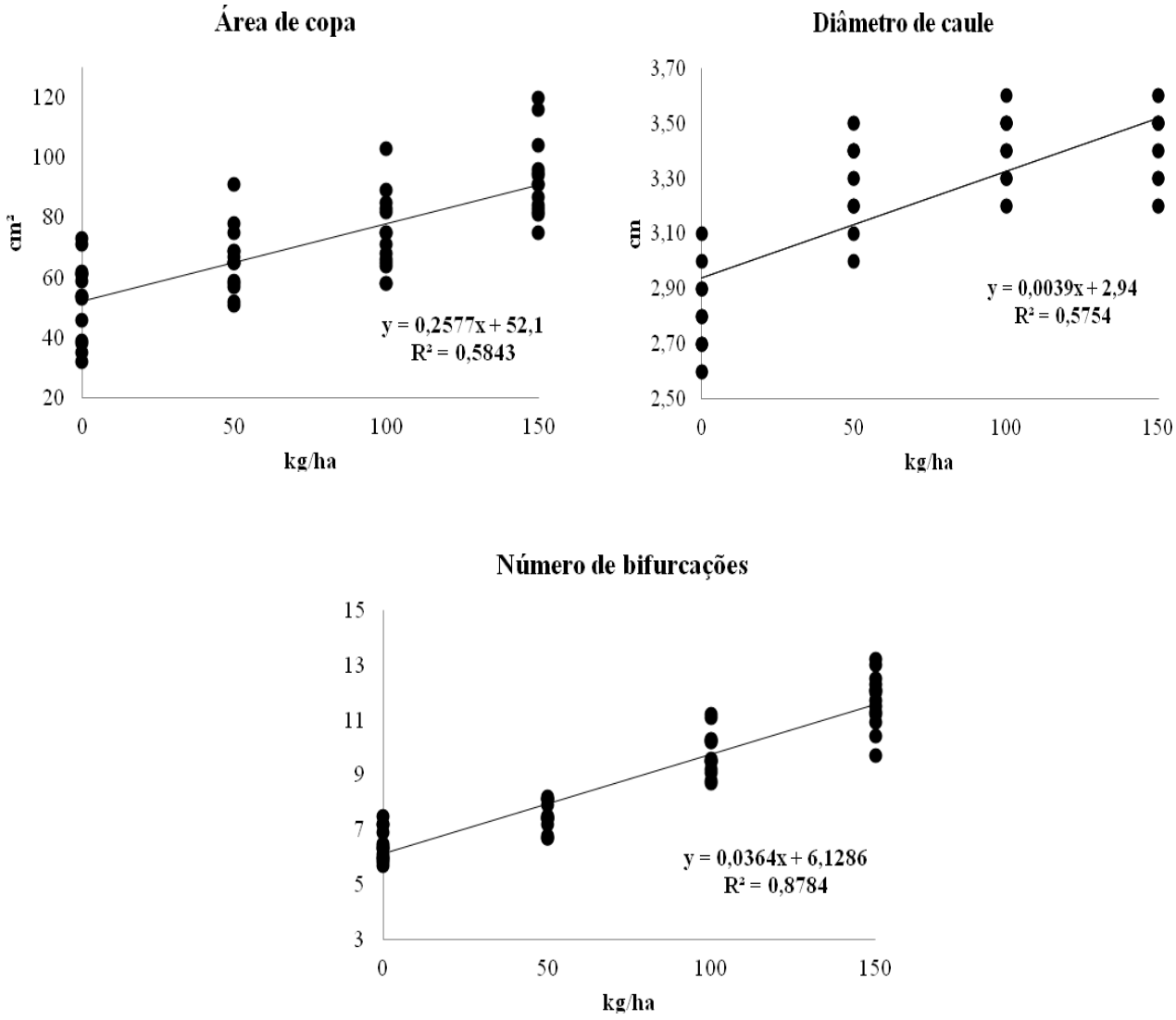

Figura 4. Características morfológicas, equações de regressão e coeficientes de determinação da maniçoba cultivada sob doses de nitrogênio aos 60 dias 


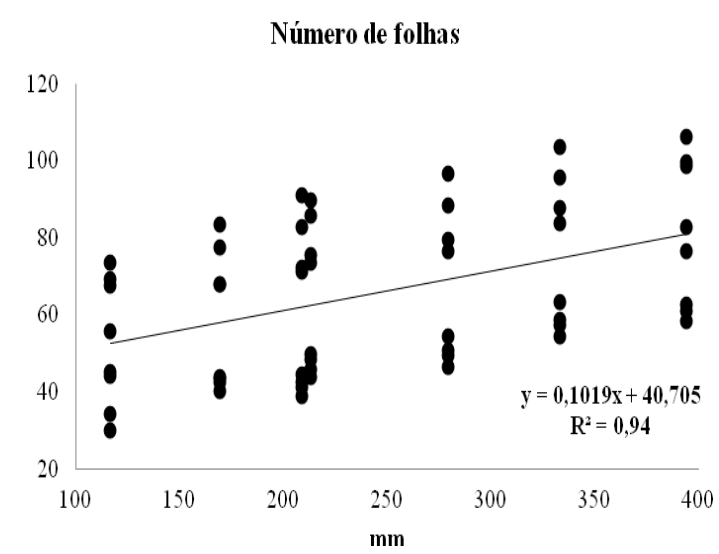

Diâmetro de caule

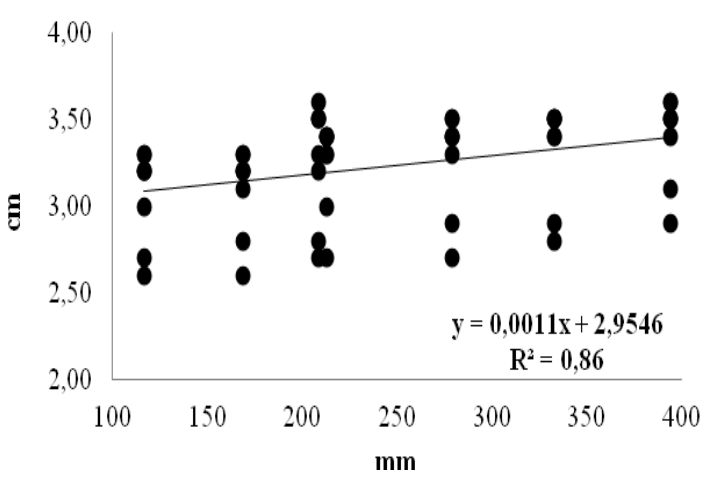

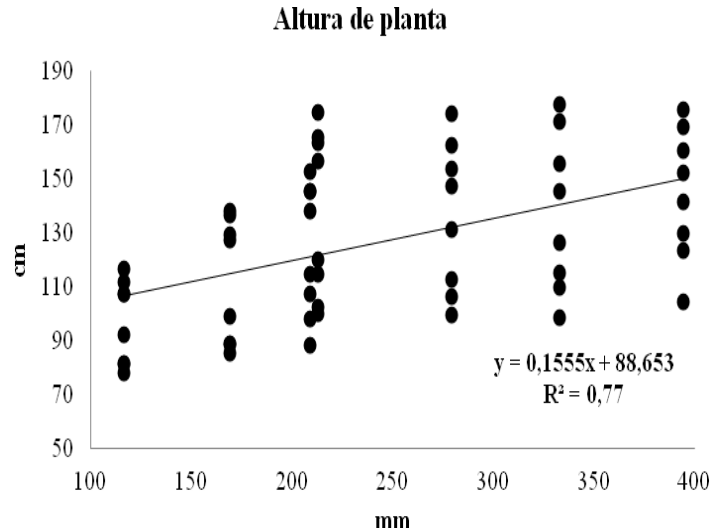

Área de copa

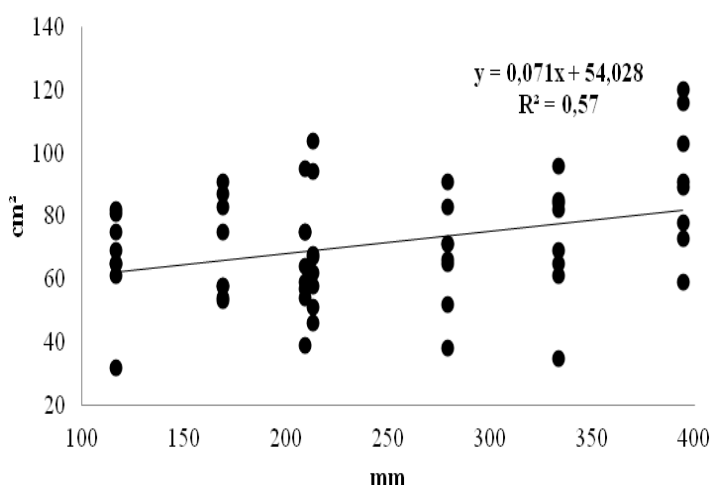

Número de bifurcações

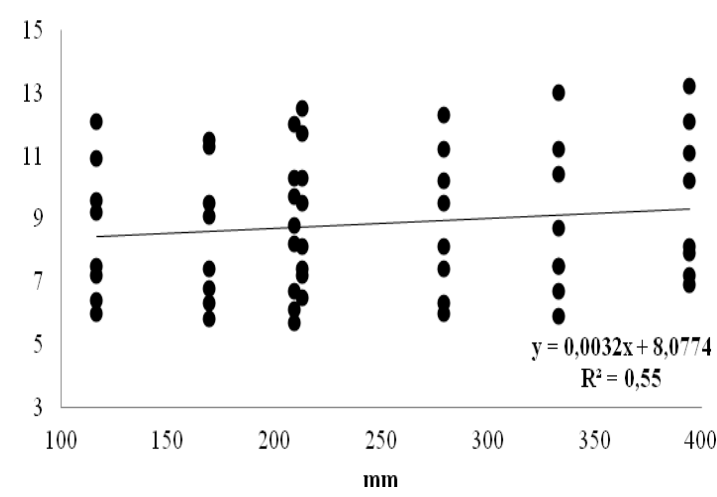

Figura 5. Características morfológicas, equações de regressão, coeficientes de determinação da maniçoba cultivada sob lâminas hídricas aos 60 dias

A resposta mais proeminente das plantas ao déficit hídrico consiste no decréscimo da área foliar, fechamento dos estômatos, aceleração da senescência e abscisão das folhas (TAIZ \& ZEIGER, 2009). Com o fechamento dos estômatos em situações de déficit hídrico, há redução da captura de $\mathrm{CO}_{2}$ pela planta, acarretando em uma situação de balanço negativo de carbono, haja vista que o processo de respiração torna-se mais proeminente com o aumento do déficit hídrico. Com a diminuição da disponibilidade de água no solo os processos de senescência e abscisão das folhas se intensificam, 
devido principalmente a diminuição da disponibilidade de nitrogênio, sendo esses teores na maioria das vezes insuficientes para suprir as necessidades de crescimento da cultura e o nitrogênio do interior da planta é retranslocado das folhas mais velhas para os pontos de crescimento.

Quando absorvido pela planta, esse nutriente aumenta o número de células em divisão e estimula o alongamento celular (SCHNYDER et al., 2000), acelerando as taxas de crescimento e desenvolvimento das plantas (MARTUSCELLO et al., 2005, 2006) e promovendo aumento expressivo no acúmulo de forragem (DURU \& DUCROCQ, 2000).

Entretanto, a intensidade da senescência depende da quantidade de nitrogênio no solo, das reservas de nitrogênio na planta e da demanda de nitrogênio dos pontos de crescimento (WOLFE et al., 1988). Sendo assim, diante do exposto, com o aumento dos valores médios das características morfológicas à medida que se elevou a disponibilidade de água no solo, todos os processos inerentes a situações de déficit hídrico foram amenizados à medida que se aumentou a disponibilidade de água no solo.

Para as características morfológicas altura de plantas, número de bifurcações, diâmetro de colmo, área de copa, produção de massa fresca e produção de massa seca, não houve interações significativas $(\mathrm{P}>0,05)$ entre os fatores lâminas hídricas e doses de nitrogênio aos 120 dias (Figura 6). Apenas para a característica número de folhas foram detectadas interações significativas $(\mathrm{P}<0,05)$ entre os fatores.

As doses de nitrogênio imprimiram efeito linear positivo $(\mathrm{P}<0,05)$ sobre as características morfológicas altura de plantas, número de bifurcações, diâmetro de caule, área de copa, produção de massa fresca e produção de massa seca aos 120 dias após corte de uniformização (Figura 6).

Excetuando-se as características número de folhas, produção de massa fresca e produção de massa seca, as demais características morfológicas apresentaram comportamento similar àquelas aos 60 dias, podendo ser os mesmos fatores responsáveis também por afetar as referidas variáveis. Observa-se que houve incrementos da ordem de 40, 55 e $34 \%$ para as características altura de plantas, número de bifurcações e área de copa, respectivamente, quando comparados os tratamentos ausentes de adubo nitrogenado e $150 \mathrm{~kg} / \mathrm{ha}$.

As características morfológicas altura de plantas, número de bifurcações, diâmetro de colmo, produção de massa fresca e produção de massa seca, apresentaram comportamento linear positivo $(\mathrm{P}<0,05)$ à medida que elevouse a disponibilidade de água no solo (Figura 4). Para a característica área de copa, não houve diferenças significativas $(\mathrm{P}>0,05)$ entre as lâminas hídricas (Figura 7).

Os fatores abióticos envolvidos no processo de crescimento e desenvolvimento das plantas no nordeste brasileiro sofrem severa estacionalidade, e as plantas sincronizam seu ciclo fenológico de acordo com as variações desses fatores. Referindo-se ao período seco (primavera e verão), este período é caracterizado principalmente por uma alta insolação e radiação, altas temperaturas diurnas e um maior fotoperíodo, quando comparado com a estação das águas (outono e inverno). Embora grande parte desses fatores seja desejável ao crescimento das plantas, o principal agravante é a disponibilidade de água no solo que tende a diminuir com a entrada do período seco. Com a ausência da água, a absorção de nutrientes do solo pela planta fica comprometida, principalmente $\mathrm{o}$ 
Rev. Bras. Saúde Prod. Anim., Salvador, v.14, n.4, p.609-623 out./dez., 2013 http://www.rbspa.ufba.br ISSN 15199940

nitrogênio, uma vez que o mesmo é 99\% transportado por fluxo de massa (TISDALE et al., 1985). A maniçoba, assim como outras plantas do estrato arbóreo-arbustivo da Caatinga, durante o período seco do ano apresenta crescimento nulo e um acúmulo negativo de biomassa e, geralmente, encontra-se em estádio de frutificação.
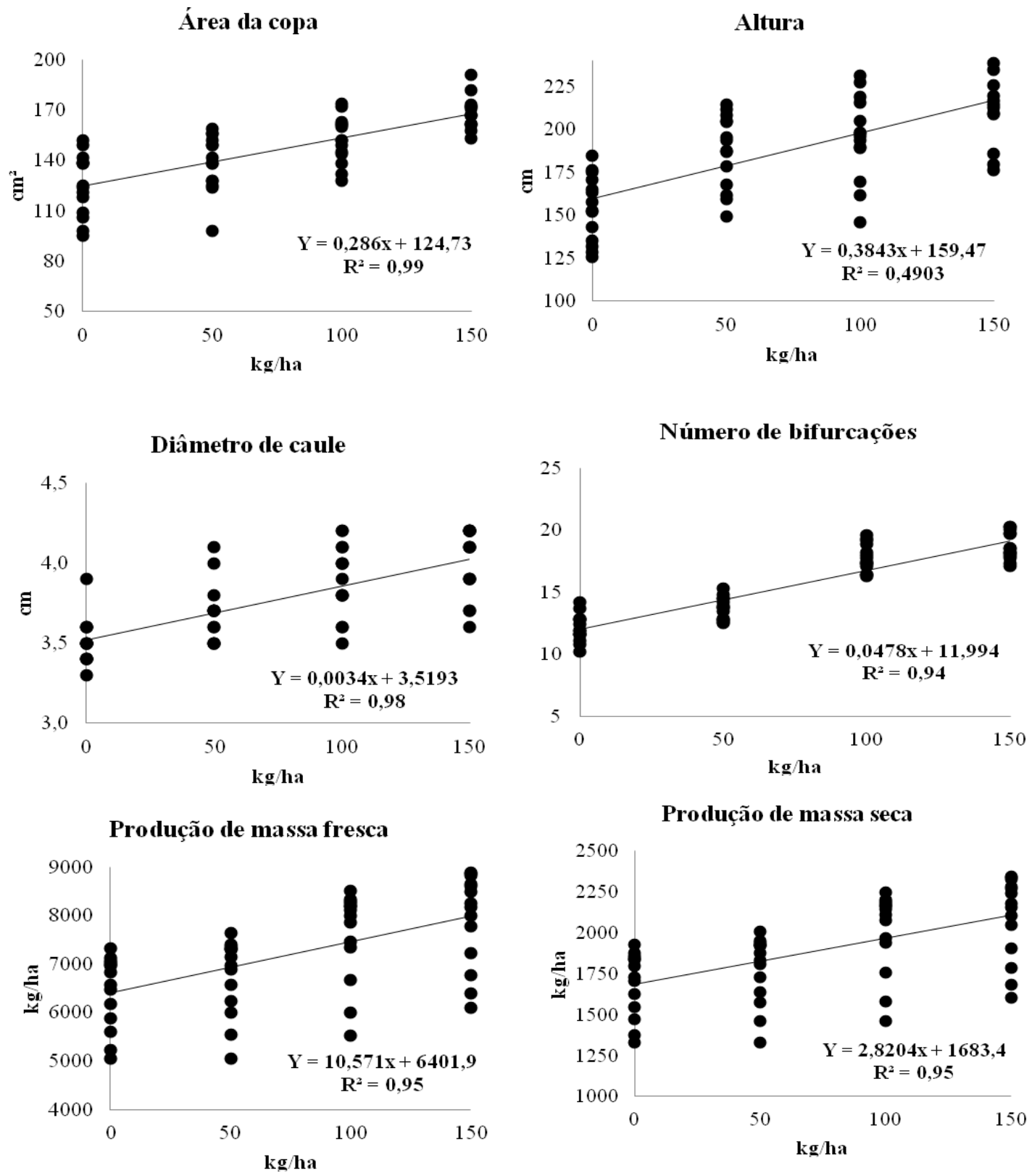

Figura 6. Características morfológicas, equações de regressão, coeficientes de determinação da maniçoba cultivada sob doses de nitrogênio aos 120 dias. 

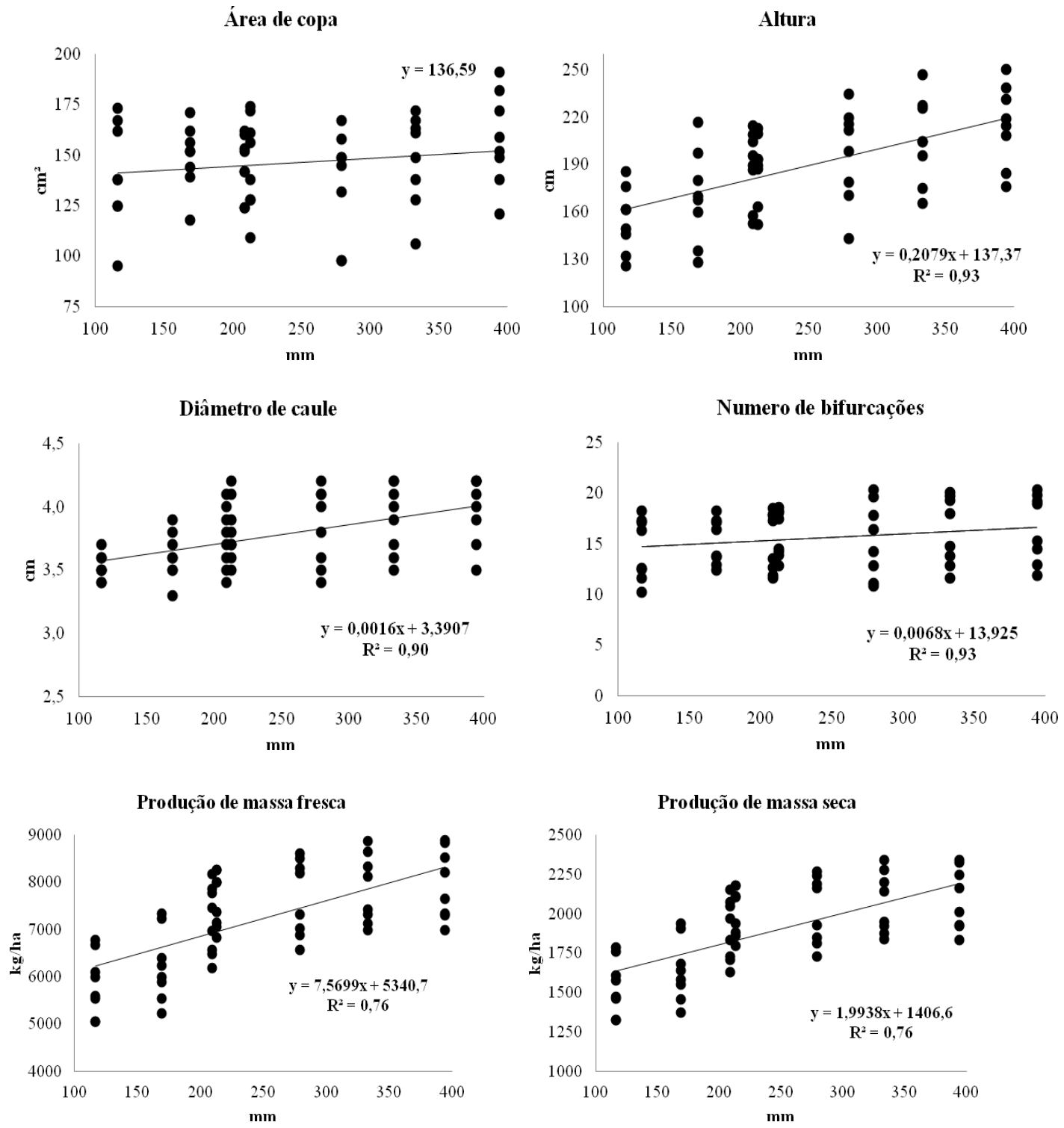

Figura 7. Características morfológicas, equações de regressão, coeficientes de determinação e coeficientes de variação da maniçoba cultivada sob lâminas hídricas aos 120 dias.

Segundo Silva et al. (2008), a água não pode ser considerada exatamente como uma fonte para o crescimento da planta, mas como um meio de dissipar o excesso de energia solar recebida pelas folhas e evitar superaquecimento, degeneração e dessecação dos tecidos vegetais. Daí, com o fornecimento não apenas de água, mas também de nutrientes (nitrogênio) durante $\mathrm{o}$ referido período, poderia de certa forma otimizar a utilização dos fatores abióticos de produção, podendo-se obter elevadas taxas fotossintéticas, gerando resultados positivos em termos de produção de biomassa. Diante do exposto, pode-se observar a otimização dos recursos abióticos de produção, por intermédio da superioridade dos valores médios das características morfológicas 
e produtivas (Figuras 6 e 7), quando comparados aos resultados obtidos por Ferreira et al. (2009) e Vasconcelos et al. (2010), avaliando a maniçoba cultivada em diferentes tipos de espaçamentos e adubações respectivamente, porém em cultivo de sequeiro.

Houve interação significativa $(\mathrm{P}<0,05)$ entre os fatores doses de nitrogênio e lâminas hídricas, para a característica número de folhas aos 120 dias (Figura
8). A referida característica apresentou efeito linear e positivo $(\mathrm{P}<0,05)$ à medida que aumentou-se a disponibilidade de água e nitrogênio. Maiores valores médios entre os tratamentos para a referida característica foram observados quando se utilizou a combinação entre a maior dose de nitrogênio e lâmina hídrica (150kg/ha de nitrogênio e 394,28mm, respectivamente).

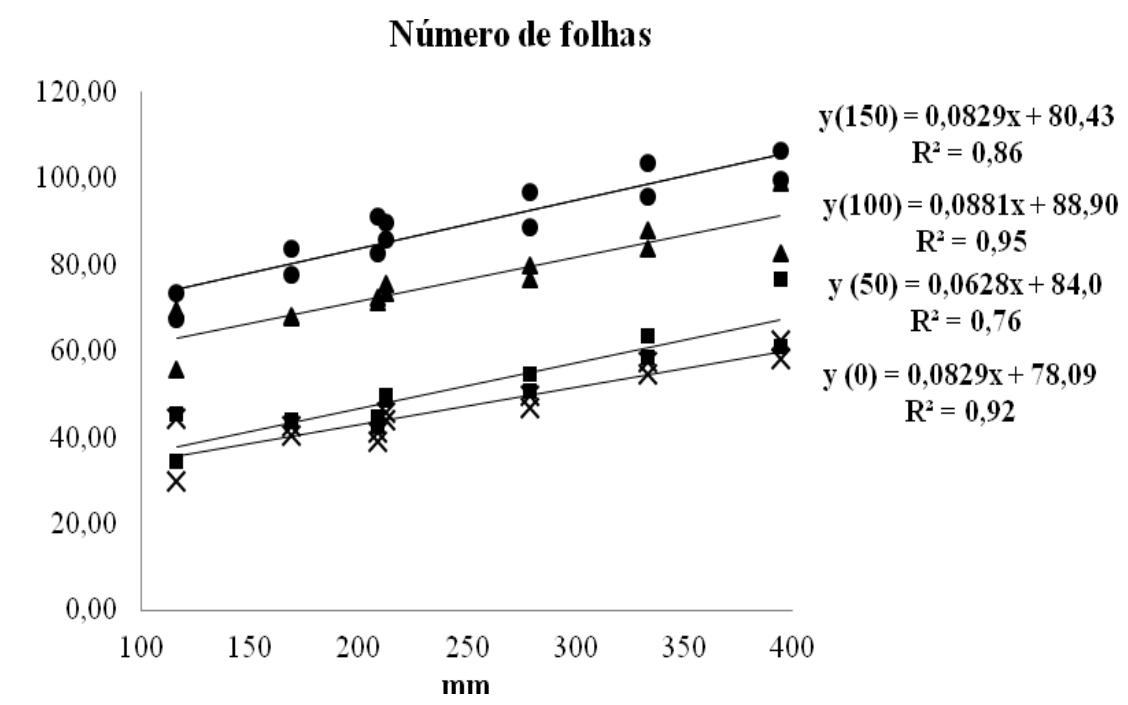

Figura 8. Equações de regressão e coeficientes de determinação da maniçoba cultivada sob lâminas hídricas e doses de nitrogênio aos 120 dias

A área foliar (IAF) é um importante fator da produção e determina o uso da água pelas plantas, e seu potencial de produtividade é severamente inibido quando exposta a déficit hídrico (FERNÁNDEZ et al., 1996). O déficit hídrico induz ao fechamento dos estômatos provocando queda na absorção principalmente de $\mathrm{CO}_{2}$ e na redução da área foliar, causando desse modo reduções na produção de biomassa pela planta, pois, a área foliar possui estreita relação com produção de forragem (MARTUSCELLO, et al.,
2005, 2006; OLIVEIRA et al., 2007) e com a interceptação de luz pelo dossel. As folhas são os componentes botânicos mais instáveis da planta, e possuem vida limitada, que pode também ser influenciada por fatores abióticos. Reforçando a afirmativa anteriormente citada, pode-se observar que independente da dose de nitrogênio, a lâmina hídrica de 116,6mm, apresentou as menores médias entre os tratamentos (Figura 8). A referida lâmina hídrica juntamente com a elevada evapotranspiração comum desse período, pode ter tornado a quantidade de água 
insuficiente para suprir as exigências da cultura, o que não contribuiu também para a diminuição dos processos de senescência e abscisão das folhas, diminuindo assim os valores médios dessa característica morfológica.

Para a característica eficiência de utilização do nitrogênio (Figura 9), houve interação entre os fatores doses de nitrogênio e lâminas hídricas, em que, para todas as doses de nitrogênio utilizadas, observou-se comportamento linear. Maiores valores para a referida característica foram observados quando maiores lâminas hídricas e menores doses de nitrogênio foram utilizadas.

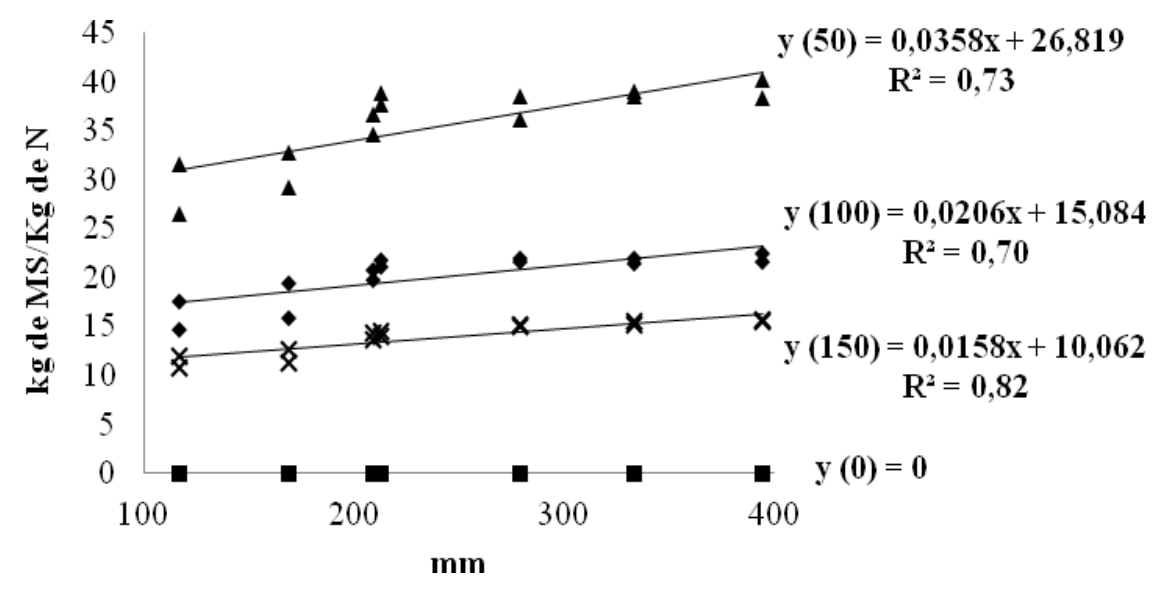

Figura 9. Eficiência de utilização de nitrogênio, equações de regressão e coeficientes de determinação da maniçoba cultivada sob doses de nitrogênio e lâminas hídricas

A redução da eficiência de utilização do nitrogênio com o aumento do fornecimento deste nutriente está de acordo com Primavesi et al. (2004), em que, estes afirmaram que a recuperação do nitrogênio pela planta diminui com o aumento da dose do fertilizante. Daí, a possível causa de se ter observado uma maior eficiência com a utilização de uma menor dose de nitrogênio $(50 \mathrm{~kg} / \mathrm{ha})$ está associada a uma maior assimilação deste e redução das perdas para o meio ambiente (solo e atmosfera), e o aumento do transporte do nutriente devido ao fornecimento concomitante de água (independente da lâmina utilizada). A diminuição da eficiência de utilização do nitrogênio, além dos motivos supracitados, pode ser advinda também de limitações morfofisiológicas (IAF, sistema radicular e nível crítico do nutriente) da própria planta em absorver e armarzenar o nitrogênio.

A redução da eficiência da utilização do nitrogênio com o aumento das doses de nitrogênio na cultura da maniçoba indica que maiores doses de fertilizante nitrogenado devem ser fracionadas mais vezes, não descartando, assim, a possibilidade da utilização de maiores doses de nitrogênio, uma vez que, maiores doses proporcionaram maior produção de massa seca (Figura 9).

Com relação a característica eficiência de utilização da água (Figura 10), não houve interação entre os fatores doses de nitrogênio. Isoladamente, para ambos os fatores, estes apresentaram comportamento linear positivo $\mathrm{e}$ 
negativo respectivamente para doses de nitrogênio (esquerda) e lâminas hídricas (direita).

O nitrogênio, por afetar diretamente a produção de biomassa da planta, proporcionou aumentos na eficiência de utilização da água, uma vez que, a produção de massa seca da planta é utilizada para estimar a referida característica.
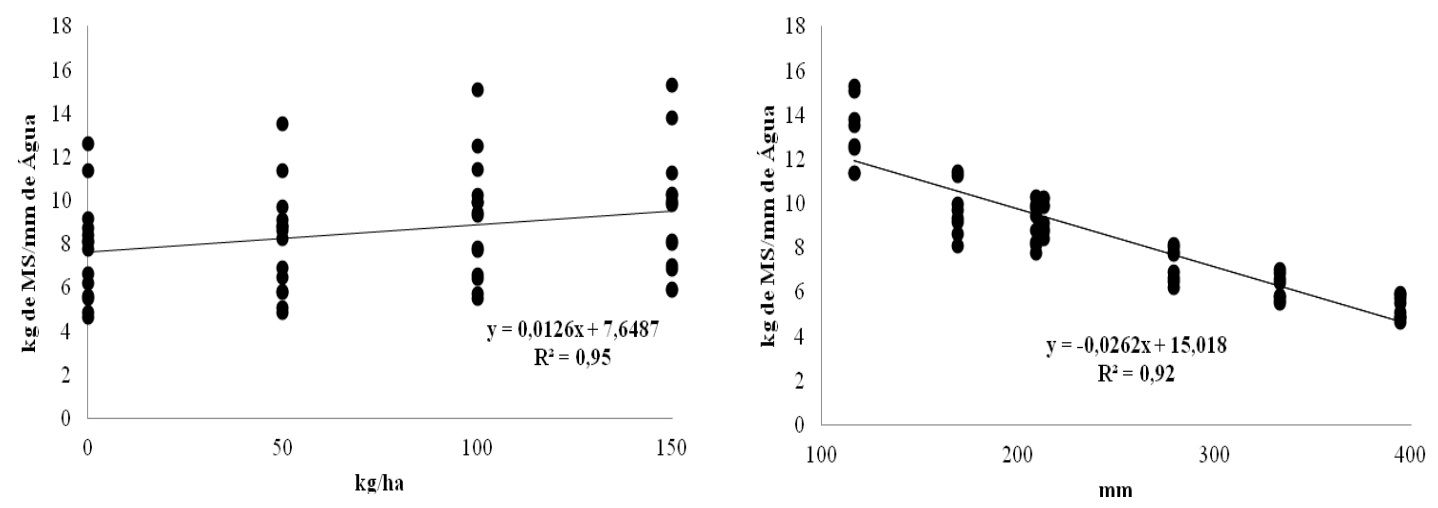

Figura 10. Eficiência da utilização da água, equações de regressão e coeficientes de determinação da maniçoba cultivada sob doses de nitrogênio (esquerda) e lâminas hídricas (direita)

Adaptada a condições de déficit hídrico, a maniçoba, quando submetida a essa situação (ou situações em que a disponibilidade de água ainda não é suficiente para o crescimento pleno da parte aérea, no caso da lâmina de $116,6 \mathrm{~mm}$ ), pode desencadear mecanismos de economia de água e nutrientes, acumulando compostos orgânicos em suas raízes tuberosas, com o intuito de manter funções metabólicas basais, necessárias para a sobrevivência da planta ou manter um reduzido número de folhas. No entanto, observase que há uma redução da eficiência de utilização da água à medida que aumentou-se sua disponibilidade, fazendo com que a planta já não necessite acumular reservas orgânicas para sobreviver, translocando água e nutrientes para a parte aérea, favorecendo desse modo a produção de biomassa (Figura 10).

É sabido que a disponibilidade de água em quantidade e a qualidade para ser utilizada em irrigação no semiárido brasileiro é limitada. A partir dos dados da característica eficiência de utilização de água quando a maniçoba recebeu diferentes lâminas hídricas (Figura 10, direita), poderia-se utilizar menores lâminas hídricas, com o intuito de explorar a alta eficiência de utilização da água intrínseca da maniçoba, gerando uma economia significante de água, podendo esta ser destinada a outros usos na propriedade rural (consumo humano ou de animais de produção). $\mathrm{O}$ aumento da dose de nitrogênio e/ou o fracionamento destas, poderia compensar a diminuição da produção de massa seca advinda da diminuição da lâmina de água.

As características morfológicas e produtivas da maniçoba são incrementadas com a utilização da adubação nitrogenada e irrigação. 


\section{REFERÊNCIAS}

ARAÚJO FILHO, J.T.; PAES, R.A.; AMORIM, P.L.; BARROS, T.S.; SILVA, R.A.; SILVA, S.C. Características morfológicas e valor nutritivo da maniçoba submetida a espaçamentos de plantio e adubações.

Revista brasileira de saúde produção animal, v.12, n.3, p.573-582, 2011.

CUNHA, D.N.F.V.; GOMES, E.S.; MARTUSCELLO, J.A.; AMORIM, P.L.; SILVA, R.C.; FERREIRA, P.S. Morfometria e acúmulo de biomassa em palma forrageira sob doses de nitrogênio. Revista brasileira de saúde e produção animal [online], v.13, n.4, p.1156-1165, 2012.

DURU, M.; DUCROCQ, H. Growth and senescence of the successive leaves on a 14 Cocksfoot tiller. Effect of nitrogen and cutting regime. Annals of Botany, v.85, p.645-653, 2000.

FERNÁNDEZ, C.J.; McINNES, K.J.; COTHREN, J.T. Water status and leaf area production in water-and nitrogenstressed cotton. Crop science, v.36, p.1224-1233, 1996.

FERREIRA, A.L.; SILVA, A.F.; PEREIRA, L.G.R.; BRAGA, L.G.T.; MORAES, S. A.; ARAÚJO, G.G.L. Produção e valor nutritivo da parte área da mandioca, maniçoba e pornunça.

Revista brasileira de saúde e produção animal [online], v. 10, n.1, p.129- 136, 2009.

MARTUSCELLO, J.A.; FONSECA, D.M.; NASCIMENTO JUNIOR, D.; SANTOS, P.M.; CUNHA, D.N.F.V.; MOREIRA, L. M. Características morfogênicas e estruturais do capimmassai submetido a adubação nitrogenada e desfolhação. Revista brasileira de Zootecnia, v.35, n.3, p.665-671, 2006.

MARTUSCELLO, J.A.; FONSECA, D.M.; NASCIMENTO JUNIOR, D.; RIBEIRO JUNIOR, J.I.; CUNHA, D.F.V.; MOREIRA, L. Características morfogênicas e estruturais do capimxaraés submetido à adubação nitrogenada e desfolhação. Revista brasileira de Zootecnia, v.34, n.5, p.1475-1482, 2005.

OLIVEIRA, R.A.; DAROS, E.; ZAMBON, J.L.C.; WEBER, H.; IDO, O.T.; BESPALHOK-FILHO, J.C.; ZUFFELLATO-RIBAS, K.C.; SILVA, D.K. T. Área foliar em três cultivares de cana-de-açúcar e sua correlação com a produção de biomassa. Pesquisa Agropecuária Tropical, v.37, p.71-76, 2007.

PRIMAVESI, A.C.; PRIMAVESI, O.; CORRÊA, L.A.; CANTARELLA, H.; SILVA, A.G.; FREITAS, A.R.; VIVALDI, L.J. Adubação nitrogenada em capim-coastcross: efeitos na extração de nutrientes e recuperação aparente do nitrogênio. Revista brasileira de Zootecnia, v.33, n.1, p.68-78, 2004.

SCHNYDER, H.; SCHÄUFELE, R.; VISSER, R.; NELSON, C. J. An integrated view of $\mathrm{C}$ and $\mathrm{N}$ uses in leaf growth zones of defoliated grasses. In: LEMAIRE, G.; HODGSON, J.; MORAES, A.; CARVALHO, P.C.de F.; NABINGER, C. (Ed.). Grassland Ecophysiology and Grazing Ecology. Wallingford: CAB International, 2000. p. 41-60.

SILVA, S.C. da; NASCIMENTO JÚNIOR, D.; EUCLIDES, V.P.B. Pastagens: conceitos básicos, produção e manejo. Viçosa: Suprema, 2008. 115p. 
TAIZ, L.; ZEIGER, E. Fisiologia vegetal. 4.ed. Porto Alegre: ArtmedEditora, 2009.

TISDALE, S.L.; NELSON, W. L.; BEATON, J. D. Soil fertility and fertilizers. 4. ed. New York: Mcmillan, 1985. 754 p.

VASCONCELOS,W.A.; SANTOS, E.M.; EDVAN, R.L.; SILVA, T.C; MEDEIROS, G.R.; SOUTO FILHO, L.T. Morfometria, produção e composição bromatológica da Maniçoba e Pornunça, em resposta a diferentes fontes de adubação. Revista Trópica: Ciências Agrárias e Biológicas, v.4, n.2, p.36, 2010.
WOLFE, D.W.; HENDERSON, D.W.; HSIAO, T.C.; ALVINO, A. Interactive water and nitrogen effects on senescence of maize: I. Leaf area duration, nitrogen distribution, and yield. Agronomy Journal, v. 80, p. 859-864, 1988.

Data de recebimento: $28 / 02 / 2013$

Data de aprovação: 02/12/2013 